\title{
Micronutrient Deficiencies in Patients after Long Term Mechanical Ventilation and Correlation to Statin Therapy
}

\author{
Wernhart $\mathbf{S}^{1,2 *}$ and Siemon $\mathrm{K}^{3}$ \\ ${ }^{1}$ Department of Prevention, Rehabilitation and Sports Medicine, Munich, Germany \\ ${ }^{2}$ Department of Cardiology, Fachkrankenhaus Kloster Grafschaft, Schmallenber, Germany \\ ${ }^{3}$ Department of Pneumology, Fachkrankenhaus Kloster Grafschaft, Schmallenber, Germany \\ *Corresponding author: Simon Wernhart, Department of Prevention, Rehabilitation and Sports Medicine, Munich, Germany
}

\begin{abstract}
ARTICLE INFO
Received: 幽 February 14, 2020

Published: 慧 February 21, 2020

Citation: Wernhart S, Siemon K. Micronutrient Deficiencies in Patients after Long-Term Mechanical Ventilation and Correlation to Statin Therapy. Biomed J Sci \& Tech Res 25(5)-2020. BJSTR. MS.ID.004272.
\end{abstract}

Abbreviations: CAD: Coronary Artery Disease; SAMS: Statin Associated Myopathy Syndrome; GFR: Glomerular Filtration Rate; COPD: Chronic Obstructive Pulmonary Disease

\section{ABSTRACT}

Background: Patients admitted to intensive care units often show deficiencies in various mincronutrients, such as zinc, selenium, vitamin D and coenzyme $Q$. In the literature controversy exists whether the latter two are influenced by statin therapy. Data is scarce on blood levels in patients after long-term invasive ventilation.

Hypothesis: We hypothesized that patients after very long-term ( $>50$ days) invasive ventilation display greater deficiencies in micronutrients than those with shorter periods on the ventilator. We also claimed that negative correlations exist between coenzyme $\mathrm{Q}$, vitamin D levels and statin therapy.

Methods: We included 93 patients (mean age 64.24years+- 11.18 vs. 66.48years+10.03 ) coming to our early rehabilitation unit after long-term invasive ventilation ( $>7$ days on the ventilator). Analysis was performed in two groups after long-term $(<50$ days) and very long-term ( $>50$ days) ventilation. Blood levels of vitamin $D$, coenzyme $\mathrm{Q}$, selenium, zinc, vitamin B12 and folate were compared between the groups and correlations of vitamin D and coenzyme $Q$ levels with statin therapy were calculated.

Results: Patients after very long-term invasive ventilation ( $>50$ days) displayed significantly lower zinc $(75.73 \mu \mathrm{g} / \mathrm{dl}+-21.24$ vs. $93.04 \mu \mathrm{g} / \mathrm{dl}+-13.46 ; \mathrm{p}<.001)$, but not selenium $(71.57 \mu \mathrm{g} / \mathrm{l}+-16.70$ vs. $78.31 \mu \mathrm{g} / \mathrm{l}+-14.31 ; \mathrm{p}=0.20)$ and vitamin $\mathrm{D}(17.44 \mu \mathrm{g} / \mathrm{l}+-$ 11.45 vs. $15.11 \mu \mathrm{g} / \mathrm{l}+-7.47 ; \mathrm{p}=0.25$ ) levels. A negative correlation between coenzyme $Q$ levels and statin therapy $(\mathrm{r}=-0.30$ and -0.25$)$ was observed.

Conclusion: Patients after long term ventilation may show different patterns of micronutrient deficiencies than patients during acute sepsis. Clinicians should be aware of a potential reduction of coenzyme $Q$ efficacy under statin therapy.

\section{Introduction}

Critically ill patients undergoing long term-ventilation have a poor prognosis and usually need a prolonged recovery period far beyond intensive care unit treatment. These patients often face multi-organ failure, either due to acute (e.g. pneumonia) or acute-on-chronic (e.g. exacerbation of chronic obstructive pulmonary disease) onset. Especially cardiac, pulmonary and renal complications often limit a patient's prognosis. Malnutrition and deficiencies in micronutrients also seem to play a pivotal role. Several studies have been performed to investigate the benefits of zinc [1-3] and selen [4,5] in sepsis patients, but do not, in themselves, improve survival. Deficiencies in folate and vitamin B12 usually lead to anemia, a common condition in critically ill patients [6]. In the last two decades considerable effort has been made to decipher the role of coenzyme $\mathrm{Q}$ as a modulator of the respiratory chain and 
its benefit as a substituent in various diseases reviews: [7,8]. As an integral component of the cellular redox-system, depletion in coenzyme $Q$ (ubichinon-ubichinol) may lead to deleterious effects in critically ill patients, although the data on the issue is scarce. However, statins, which have a class I recommendation in Coronary Artery Disease (CAD) and are therefore widely used in critically ill patients (who often have concomitant CAD), may reduce Coenzyme $\mathrm{Q}(\mathrm{CoQ})$ activity, since both cholesterol and CoQ require mevalonic acid as a precursor [9].

This, in turn, may translate into an unfavorable redox state and foster Statin Associated Myopathy Syndrome (SAMS) [10]. On the other hand, statin toxicity on the innate redox system may be used to increase antitumor activity [11]. Vitamin D has raised a lot of attention during the last decade, since it seems to display pleiotropic effects apart from its central role in bone metabolism. However, lately a randomized controlled trial did not show a significant difference in the incidence of type 2 diabetes in highrisk patients supplementing 4000IE/day over a period of 2.5 years [12]. Although knock out of vitamin D-receptor in mice has led to the development of arterial hypertension and left ventricular hypertrophy [13], the VITAL study was not able to transfer these findings into reduced cardiovascular mortality and lower incidence of cancer in humans in a randomized trial [14]. Ginde and colleagues did not find a significant difference in 90-day-mortality with early high-dose vitamin D substitution in an intensive care setting [15]. Contradictory data exists on the influence of low vitamin D levels and SAMS: Pennissi and colleagues found an association between lower vitamin D levels and a higher prevalence of SAMS [16]. Substitution has recently been shown to enhance statin compliance in elderly patients [17]. It was also proposed that vitamin D deficiency independently causes myopathy and thus increases the effect of SAMS [18]. However, other studies did not find an association between low vitamin D and SAMS [19].

To our knowledge, no data exists on the prevalence of micronutrient deficiencies in patients surviving long-term ventilation. The aim of our study was to analyze whether there were differences in the micronutrient status of zinc, selen, coenzyme $Q$ and vitamin $D$ in survivors of long-term (seven to 50 days) and very long-term (more than 50 days) invasive ventilation. We hypothesized that longer invasive ventilation would lead to a more pronounced deficiency in micronutrients (Hypothesis 1). Furthermore, we claimed that there is an inverse correlation between vitamin $\mathrm{D}$, coenzyme $Q$ levels and statin therapy (Hypothesis 2).

\section{Materials and Methods}

Institutional review board approval as well as informed consent were obtained for data acquisition and analysis. The study was not funded.

\section{Subjects and Design}

Patients who entered our early rehabilitation unit after longterm invasive ventilation (defined as at least seven days of invasive ventilation over an oro-tracheal tube or a tracheostomy) were enrolled into our study. Eligibility to the study met the same criteria as entrance to the early rehabilitation unit itself: Patients had to have an estimated life expectancy of at least six months determined by two experienced physicians. Furthermore, the potential of rehabilitation was assessed by the same two physicians in terms of

a) Mental status

b) Physical capabilities

c) Cognitive impairments.

Rehabilitative potential was defined as an expected ability to perform "activities of daily living" after a training period of four weeks. There was no age limit to our study. Patients entering our unit had to be extubated or had to have a tracheostoma. Previous supplementation of vitamin D, coenzyme Q, zinc, selen, vitamin B12 and folate had to be excluded, enteral and/or parenteral nutrition were performed according to established standards of intensive care medicine. The aim of our early rehabilitation unit is to re-integrate critically ill patients coming directly from the intensive care unit into activities of daily living. Our team consists of physicians with a specialty in intensive care medicine, nurses trained in intensive care as well as early mobilization techniques and physiotherapists with an emphasis on logopedics, management of dysphagia and electrotherapy.

Exclusion criteria were prolonged necessity of vasopressors and iv- sedatives and a life expectancy of less than six months. Patients without "rehabilitative potential" as defined above were excluded. Out of the clinical observation of aggravated recovery after invasive ventilation beyond 50 days we separated our population into critically ill patients with more than 50 days of invasive ventilation and those with less than 50 days. On admission to our unit whole blood analysis of total 25-OH-vitamin D, consisting of 25-OHvitamin D2 and 25-OH-vitamin D3, was performed with Liquid Chromotography Mass Spectroscopy, LC-MS (lower reference limit: $20 \mu \mathrm{g} / \mathrm{l}$ ). Since a number of critically ill patients had survived prolonged sepsis periods, we also analyzed whole blood levels of zinc (lower reference limit $60 \mu \mathrm{g} / \mathrm{dl}$ ), selen (lower reference limit $50 \mu \mathrm{g} / \mathrm{l}$ ), coenzyme $\mathrm{Q}$ (lower reference limit $0,4 \mathrm{mg} / \mathrm{l}$ ), vitamin B12 (lower reference limit 210ng/l), folate (lower reference limit $5,4 \mu \mathrm{g} / \mathrm{l})$.

NT pro BNP (upper reference limit dependent on age) was measured as a marker of chronic heart failure and cystatin $\mathrm{C}$ clearance (lower reference limit $>90 \mathrm{ml} / \mathrm{kg} / \mathrm{m}^{2}$ ) was preferred to established Glomerular Filtration Rate (GFR) estimation via MDRD formula due to decreased muscle mass (and thus under estimation) to assess renal function. We analyzed the list of medications of our patients. The statin dose was expressed as potency equivalents to the lead substance Simvastatin (a value of 1 refers to $10 \mathrm{mg}$ Simvastatin and would equal $5 \mathrm{mg}$ of Atorvastatin). Differences in usage between the groups were analyzed as well as their correlation with vitamin D and coenzyme Q levels. 


\section{Statistical Analysis}

Statistical analysis was performed with Microsoft Excel 2007 and SPSS 23. Due to the sufficient sample size and the expected robustness of a t-distribution, between- group differences were calculated with a two-sided t-test $($ alpha $<.05)$ and correlations were assessed with Pearson's correlation coefficients. Mean values and standard deviations were computed.

\section{Results}

\section{Anthropometric Results}

We included 93 patients (51 males, 42 females) with a mean age of 65.45 years+-10.58. Seven had a history of stroke $(7.53 \%)$, 24 of coronary or peripheral artery disease (25.81\%). 65 patients suffered from arterial hypertension (69.89\%) and 25 from diabetes mellitus (26.88\%). The reason for invasive ventilation was exacerbation of Chronic Obstructive Pulmonary Disease (COPD) in most case $(n=35 ; 37.63 \%)$, followed by pneumonia $(n=24 ; 25.81 \%)$. Respiratory failure due to obesity-hypoventilation syndrome (OHS, $\mathrm{n}=14 ; 15.05 \%)$, cancer $(\mathrm{n}=4 ; 4.30 \%)$, coronary artery disease $(n=6 ; 6.45 \%)$, abdominal surgery $(n=8 ; 8.60 \%)$ and pneumothorax $(n=2 ; 2.15 \%)$ occurred less often. Table 1 illustrates baseline characteristics of the two groups. Levels of vitamin D were below the lower reference limit in both groups ( $>50$ days: $17.44 \mu \mathrm{g} / \mathrm{l}+-$ 11.45 vs. $<50$ days: $15.11 \mu \mathrm{g} / \mathrm{l}+-7.47$ ), with no significant difference between the groups $(\mathrm{p}=0.25)$. There were no correlations between vitamin $D$ level and use of statins $(r=0.04$ for the group $>50$ days vs. $r=-0.01$ for the group $<50$ days)

Table 1: Baseline characteristics of the two groups. CAD/ PAD: coronary artery and peripheral artery disease. 1 pack year of nicotine equals 1 pack of cigarette per day for 1 year. COPD: chronic obstructive pulmonary disease. OHS: obesity hypoventilation syndrome. Percentages and standard deviations in brackets, where appropriate.

\begin{tabular}{|c|c|}
\hline $\begin{array}{l}>50 \text { days on invasive ventilation } \\
\qquad(n=43)\end{array}$ & $\begin{array}{l}<50 \text { days on invasive ventilation } \\
\qquad(n=50)\end{array}$ \\
\hline Mean age: 64.24 years+- 11.18 & Mean age: $66.48+-10.03$ \\
\hline $\begin{aligned} \text { Sex: } & 27 \text { males }(62.79 \%), 16 \\
& \text { females }(37.21 \%)\end{aligned}$ & $\begin{array}{c}\text { Sex: } 24 \text { males (48\%), } 26 \text { females } \\
(52 \%)\end{array}$ \\
\hline History of stroke: $n=4(9.3 \%)$ & History of stroke: $n=3(6.0 \%)$ \\
\hline History of CAD/PAD: $n=7$ (16.28\%) & History of CAD/PAD: $n=17(34.0 \%)$ \\
\hline $\begin{array}{l}\text { History of arterial hypertension: } \\
\qquad n=31(72.09 \%)\end{array}$ & $\begin{array}{l}\text { History of arterial hypertension: } \\
\qquad \mathrm{n}=34(68.0 \%)\end{array}$ \\
\hline $\begin{array}{l}\text { History of diabetes: } \mathrm{n}=11 \\
\qquad(25.58 \%)\end{array}$ & History of diabetes: $\mathrm{n}=14(28.0 \%)$ \\
\hline $\begin{array}{l}\text { Mean pack years of nicotine: } 41.63 \\
\qquad(+-29.13)\end{array}$ & $\begin{array}{l}\text { Mean pack years of nicotine: } 31.63 \\
(+-20.92)\end{array}$ \\
\hline $\begin{array}{l}\text { Mean days on invasive ventilation: } \\
\qquad 100.23+-49.44\end{array}$ & $\begin{array}{l}\text { Mean days on invasive ventilation: } \\
\qquad 21.58+-14.18\end{array}$ \\
\hline Reasons for invasive ventilation & Reasons for invasive ventilation \\
\hline $\begin{array}{l}\text { Exacerbation of COPD: } n=14 \\
\qquad(32.56 \%)\end{array}$ & $\begin{array}{l}\text { Exacerbation of COPD: } n=21 \\
(42.0 \%)\end{array}$ \\
\hline Pneumonia: $n=13$ (30.24\%) & Pneumonia: $\mathrm{n}=11(22.0 \%)$ \\
\hline
\end{tabular}

\begin{tabular}{|c|c|}
\hline Cancer: $\mathrm{n}=2(4.65 \%)$ & Cancer: $\mathrm{n}=2(4.0 \%)$ \\
\hline $\begin{array}{c}\text { Coronary Artery Disease: } \mathrm{n}=3 \\
(6.98 \%)\end{array}$ & $\begin{array}{c}\text { Coronary Artery Disease: } \mathrm{n}=3 \\
(6.0 \%)\end{array}$ \\
\hline OHS: $\mathrm{n}=8(18.60 \%)$ & OHS: $\mathrm{n}=6(12.0 \%)$ \\
\hline Abdominal surgery: $\mathrm{n}=3(6.97 \%)$ & Abdominal surgery: $\mathrm{n}=5(10.0 \%)$ \\
\hline Pneumothorax: $\mathrm{n}=1(2.36 \%)$ & Pneumothorax: $\mathrm{n}=1(2.0 \%)$ \\
\hline
\end{tabular}

\section{Zinc $[\mu \mathrm{g} / \mathrm{dl}]$}

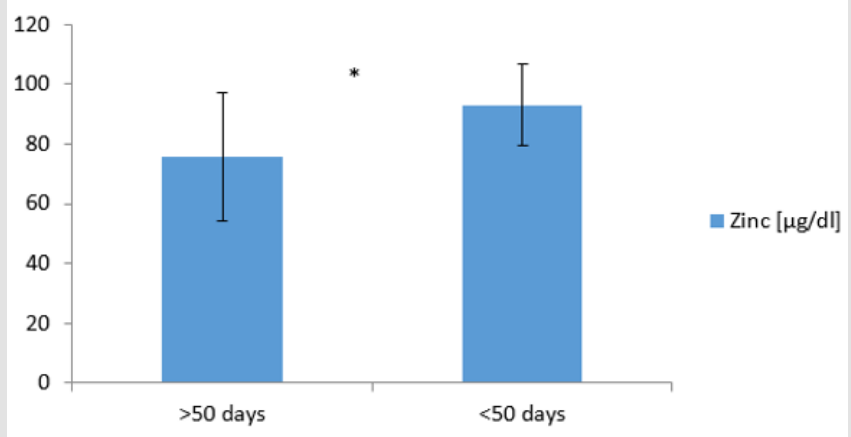

Figure 1: Zinc levels in whole blood at admission to the early rehabilitation unit in the group with very long-term ( $>50$ days) and long-term ( $<50$ days) duration of invasive ventilation. The asterisk denotes significance at alpha<.05, standard deviations are indicated.

\section{VitaminD $[\mu \mathrm{g} / \mathrm{l}]$}

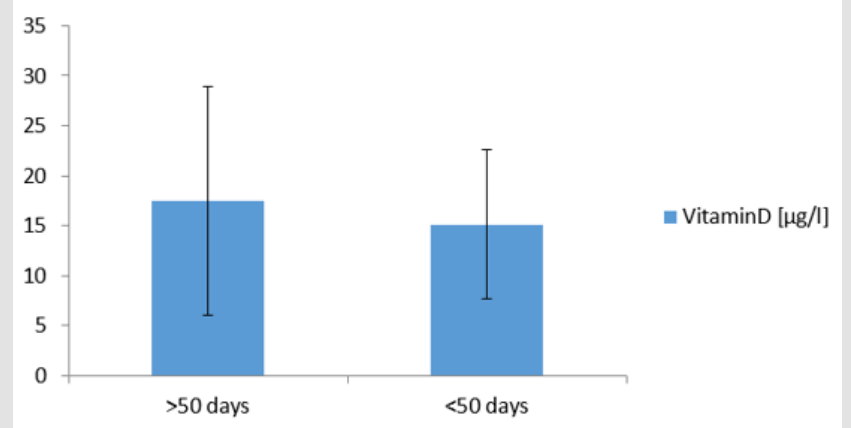

Figure 2: Vitamin D levels in whole blood at admission to the early rehabilitation unit in the group with very longterm ( $>50$ days) and long-term ( $<50$ days) duration of invasive ventilation. The asterisk denotes significance at alpha $<.05$, standard deviations are indicated.

Quite moderate correlations were achieved for statin use and coenzyme $Q$ levels ( $>50$ days: $r=-0.30$ vs $<50$ days $r=-0.25$ ). As expected, the group with longer invasive ventilation ( $>50$ days) had significantly worse renal function $\left(38.64 \mathrm{ml} / \mathrm{min} / \mathrm{m}^{2}+-21.61\right.$ vs. $55.73 \mathrm{ml} / \mathrm{min} / \mathrm{m}^{2}+-24.84 ; \mathrm{p}<.001$ ) and higher levels of NTproBNP (2304.48pg/ml+-3840.55 vs. $921.06 \mathrm{pg} / \mathrm{ml}+-1085.77 ; \mathrm{p}=.017$ ), although with a quite large range. Interestingly, zinc $(75.73 \mu \mathrm{g} / \mathrm{dl}+-$ 21.24 vs. $93.04 \mu \mathrm{g} / \mathrm{dl}+-13.46 ; \mathrm{p}<.001)$, but not selenium $(71.57 \mu \mathrm{g} /$ $\mathrm{l}+-16.70$ vs. $78.31 \mu \mathrm{g} / \mathrm{l}+-14.31 ; \mathrm{p}=0.20$ ), vitamin B12 (544.28ng/ $\mathrm{l}+-177.37$ vs. $545.43 \mathrm{ng} / \mathrm{l}+-255.32 ; \mathrm{p}=0.98)$, folate $(12.78 \mu \mathrm{g} / \mathrm{l}+-$ 6.41 vs. $13.10 \mu \mathrm{g} / \mathrm{l}+-6.91 ; \mathrm{p}=0.82)$ and coenzyme $\mathrm{Q}(0.91 \mathrm{mg} / \mathrm{l}+-$ 0.46 vs. $0.74 \mathrm{mg} / \mathrm{l}+-0.34 ; \mathrm{p}=0.23$ ) were significantly lower in pa- 
tients with $>50$ days of invasive ventilation (Figures 1-4). Statin use $(\mathrm{p}=0.16)$ did not differ between the groups, neither did nicotine consumption, measured in pack years (41.63years+-29.13 vs. 31.30years+-20.92; $\mathrm{p}=0.05$ ).

\section{Coenzyme Q [mg/l]}

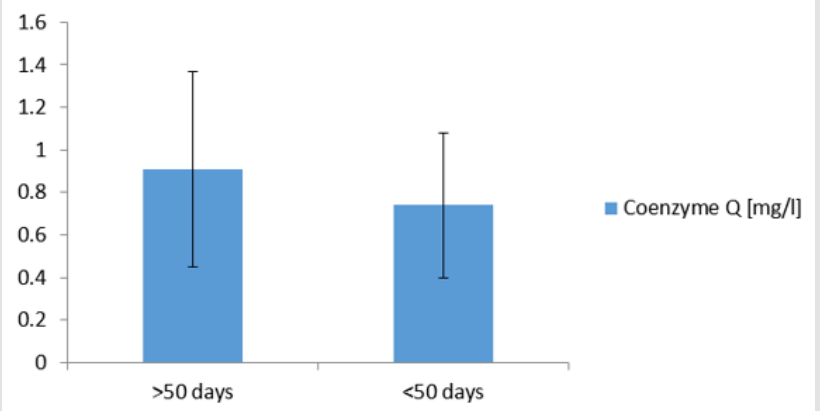

Figure 3: Coenyzme $Q$ levels in whole blood at admission to the early rehabilitation unit in the group with very long-term ( $>50$ days) and long-term ( $<50$ days) duration of invasive ventilation. The asterisk denotes significance at alpha $<.05$, standard deviations are indicated.

\section{Selenium $[\mu \mathrm{g} / \mathrm{I}]$}

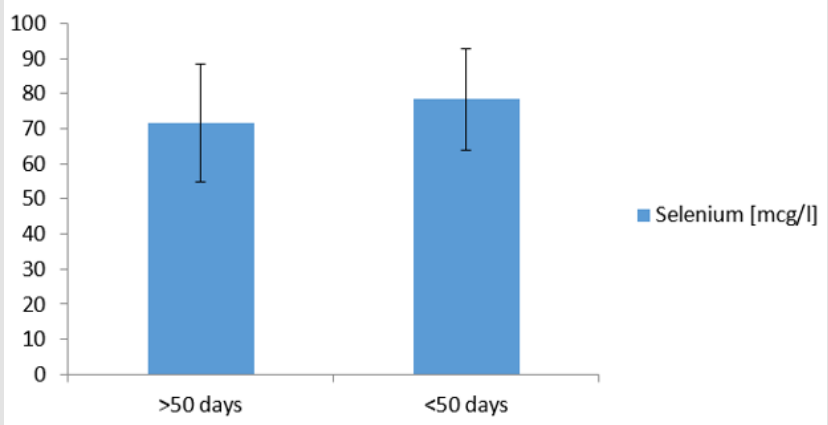

Figure 4: Selenium levels in whole blood at admission to the early rehabilitation unit in the group with very longterm ( $>50$ days) and long-term ( $<50$ days) duration of invasive ventilation. The asterisk denotes significance at alpha<.05, standard deviations are indicated.

\section{Discussion}

We analyzed patients admitted to the early rehabilitation unit of our hospital after long- term (> seven days) invasive ventilation. Following clinical experience that patients with more than two months on invasive ventilation bear a poorer prognosis than those with shorter ventilation time, we separated our patients into two groups ( $>$ and $<50$ days of invasive ventilation). The most common reason for admission to our ward was respiratory failure, especially exacerbated COPD and pneumonia. The most common risk factor for COPD is smoking, which was manifest in both groups (41.63 vs. 31.30 pack years), with a trend towards more smoking in the group of longer ventilation ( $\mathrm{p}=0.05)$.Smoking causes oxidative stress to the cell, which may lead to the assumption that smokers may show lower coenzyme Q levels. However, the two groups in our population did not differ significantly. We found that the group of prolonged ventilation displayed significantly worse renal function, which is not surprising. Additionally, NTproBNP, as a marker of chronic heart failure, was significantly higher. The quite large standard deviation may be explained by a considerable number of acute pneumonias in otherwise healthy subjects who, despite prolonged invasive ventilation, were able to retain their cardiac function. On the other hand, COPD patients, who often have other relevant comorbidities, especially coronary artery disease and chronic heart failure, may already display relevant elevations of NTproBNP at the very beginning of intensive and rehabilitative care treatment.

We found zinc levels to be significantly more depleted in the group with longer invasive ventilation, although mean values were still above the low reference limit. Selenium, coenzyme Q B12, folate and vitamin D did not show differences between the groups. Our study stands in contrast to the findings of Moghadam and colleagues, who did not find reduced zinc and selenium levels at patient admission to the Intensive Care Unit (ICU). This, however, was a clearly different population, as admission was due to severe sepsis [5]. Contrary to this, Cirino Ruocco et al. found both reduced zinc and selenium levels in sepsis patients at ICU admission [4]. Zinc exerts several functions within the cell, ranging from the regulation of transcription, working as a second messenger in immune cells and as co-factor for various intracellular enzymes. Furthermore, zinc deficiency was shown to depress T-cells in total and to produce a Th1-Th2-cell shift and, most of all, zinc depletion was described as a co-factor for increased mortality in sepsis patients [1-3]. Our study of critically ill adult patients adds new data in a way that zinc depletion in long-term invasive ventilation may take several weeks to be measurable in whole blood.

The observation that selenium and coenzyme $Q$ were not different in our two groups may be due to the difficulty to measure blood levels. Although measurements are routinely performed in whole blood, measurement errors may become more evident in intra-mitochondrial nutrients such as coenzyme Q. Moreover, deduction of clinical symptoms and prognoses from lab values is always critical. Similarly, to zinc, selenium has been extensively studied in sepsis [4,5], but, to our knowledge, no larger study exists on selenium status in long-term invasive ventilation. In this population chronic inflammation and catabolism lead to an immense workload of the innate redox system, with selenium as an integral co-factor of responsible enzymes, such as glutathion peroxidase. To verify, whether additional selenium supplementation would be of clinical benefit in our population, further studies will be necessary. Although we did not find significant differences between coenzyme $Q$ levels in our two groups, it was negatively correlated with statin use ( $r=-0.30$ vs. $r=-0.25$ ). The whole blood levels of coenzyme $Q$ were mainly within the lab's reference frame, a clinical relationship between blood measurement and intra-mitochondrial depletion in vivo may, however, not be accurate. From a clinical perspective, it may be reasonable to substitute coenzyme Q during long-term statin therapy in patients at risk to develop SAMS [10,20,21]. 
In clinical practice intensive care physicians often have to weigh the benefits of statin continuation against potential side effects, such as SAMS. In myocardial infarction the decision may be easier, because the benefits may clearly outweigh its potential harm. However, in non-cardiac long-term ventilated patients critical illness polyneuro-and myopathy are common problems. Muscle atrophy itself may foster symptoms and it becomes harder for the clinician to decide who to blame, the underlying disease or statin myopathy. Conflicting data exists on the relationship between vitamin D levels and the occurrence of SAMS [14-22]. $\mathrm{Wu}$ et al. provided data that intake of vitamin $\mathrm{D}$ enhanced the compliance to Simvastatin [17]. Additionally, Verdoia et al. found that high intensity statin therapy increased vitamin D levels after acute coronary syndrome [23]. Furthermore, myopathy risk during statin intake may also be facilitated by certain vitamin $\mathrm{D}$ receptor mutations [24].

Caution is warranted in interpreting these results, since the available association studies do not allow to draw causal conclusions on the influence of statins on vitamin D levels. In our population we found no difference between the two groups in terms of vitamin D levels. However, the values in both groups were basically below the lower reference limit. A lot of discussions have been going on in the literature about reference values for treatment initiation. While there is agreement on treatment initiation below a cut-off level of $<12 \mathrm{ng} / \mathrm{ml}$ to prevent osteomalacia, no clear values exist for other bodily functions requiring vitamin D [13]. Our study adds valid information that long-term intensive care patients have rather low levels of vitamin D. The clinical relevance of this finding has to be further explored in randomized trials.

\section{Conclusion}

In our very unique population of patients after long-term ventilation we found significantly lower levels of zinc, worse renal and cardiac function beyond 50 days on the ventilator, while levels of coenzyme $Q$ vitamin $\mathrm{D}$ and selenium did not differ. It could be hypothesized that our group displays a different pattern on micronutrient deficiencies than acute sepsis patients. No relevant correlation was found between vitamin D levels and statin dosage, while coenzyme $Q$ levels were negatively correlated with statin use. These data emphasize that clinicians treating long-term ventilated patients have to monitor their patients closely and may be forced to reduce statin dose in the abscence of acute vessel injury in case of clinical symptoms, such as myopathy. Vitamin D levels were generally below the lower reference level, but whether substitution should be promptly initiated remains to be seen in the absence of randomized trials proofing a mortality benefit.

\section{Competing Interests}

We declare that we have no competing interests.

\section{References}

1. Ganatra HA, Varisco BM, Harmon K, Lahni P, Opoka A (2017) Zinc supplementation leads to immune modulation and improved survival in a juvenile model of murine sepsis. Innate Immun 23(1): 67-76.

2. Krones CJ, Klosterhalfen B, Butz N, Hoelzl F, Junge K, et al. (2005) Effect of zinc pretreatment on pulmonary endothelial cells in vitro and pulmonary function in a porcine model of endotoxemia. J Surg Res 123(2): 251-256.

3. Nowak JE, Harmon K, Caldwell CC, Wong HR (2012) Prophylactic zinc supplementation reduces bacterial load and improves survival in a murine model of sepsis. Pediatr Crit Care Med J Soc Crit Care Med World Fed Pediatr Intensive Crit Care Soc 13(5): e323-e329.

4. Cirino Ruocco MA, Pacheco Cechinatti ED, Barbosa F Jr, Navarro AM (2018) Zinc and selenium status in critically ill patients according to severity stratification. Nutrition 45: 85-89.

5. Moghaddam OM, Lahiji MN, Moghaddas A, Farasatinasab M, Nasiripour S (2017) The Content of Plasma Selenium in Early Admitted Septic Patients. J Res Pharm Pract 6(1): 52-55.

6. Molina López J, Florea D, Quintero Osso B, De la Cruz AP, Rodríguez Elvira M (2016) Pyridoxal-5'-phosphate deficiency is associated with hyperhomocysteinemia regardless of antioxidant, thiamine, riboflavin, cobalamine, and folate status in critically ill patients. Clin Nutr 35(3): 706-712.

7. Rosenfeldt F, Hilton D, Pepe S, Krum H (2003) Systematic review of effect of coenzyme Q10 in physical exercise, hypertension and heart failure. Biofactors 18(1-4): 91-100.

8. Berger MM (2020) Do micronutrient deficiencies contribute to mitochondrial failure in critical illness? Curr Opin Clin Nutr Metab Care 23(2): 102-110.

9. Willis RA, Folkers K, Tucker JL, Ye CQ Xia LJ (1990) Lovastatin decreases coenzyme Q levels in rats. Proc Natl Acad Sci USA 87(22): 8928-8930.

10. Raizner AE (2019) Coenzyme Q10. Methodist Debakey Cardiovasc J 15(3): 185-191.

11. Mc Gregor GH, Campbell AD, Fey SK, Tumanov S, Sumpton D, et al. (2020) Targeting the Metabolic Response to Statin-Mediated Oxidative Stress Produces a Synergistic Antitumor Response. Cancer Res 80(2): 175-188.

12. Pittas AG, Dawson Hughes B, Sheehan P, Ware JH, Knowler WC, et al. (2019) Vitamin D Supplementation and Prevention of Type 2 Diabetes. N Engl J Med 381(6): 520-530.

13. Bouillon R, Marcocci C, Carmeliet G, Bikle D, White JH, et al. (2019) Skeletal and Extraskeletal Actions of Vitamin D: Current Evidence and Outstanding Questions. Endocr Rev 40(4): 1109-1151.

14. Manson JE, Cook NR, Lee IM, Christen W, Bassuk SS, et al. (2019) VITAL Research Group. Vitamin D Supplements and Prevention of Cancer and Cardiovascular Disease. N Engl J Med 380(1): 33-44.

15. National Heart, Lung, and Blood Institute PETAL Clinical Trials Network, Ginde AA, Brower RG, Caterino JM, Finck L, Banner-Goodspeed VM, et al. Early High-Dose Vitamin D3 for Critically Ill, Vitamin D-Deficient Patients. N Engl J Med 381(26): 2529-2540.

16. Pennisi M, Di Bartolo G, Malaguarnera G, Bella R, Lanza G, et al. (2019) Vitamin D Serum Levels in Patients with Statin-Induced Musculoskeletal Pain. Dis Markers 2019: 3549402.

17. Wu Z, Camargo CA Jr, Khaw KT, Waayer D, Lawes CMM, et al. (2018) Effects of vitamin D supplementation on adherence to and persistence with long-term statin therapy: Secondary analysis from the randomized, double-blind, placebo-controlled ViDA study. Atherosclerosis 273: 5966. 
18. Riche KD, Arnall J, Rieser K, East HE, Riche DM (2016) Impact of vitamin D status on statin-induced myopathy. J Clin Transl Endocrinol 6: 56-59.

19. Taylor BA, Lorson L, White CM, Thompson PD (2017) Low vitamin D does not predict statin associated muscle symptoms but is associated with transient increases in muscle damage and pain. Atherosclerosis 256: $100-104$.

20. Taylor BA, Lorson L, White CM, Thompson PD (2015) A randomized trial of coenzyme Q10 in patients with confirmed statin myopathy. Atherosclerosis 238(2): 329-335.

21. Parker BA, Gregory SM, Lorson L, Polk D, White CM (2013) A randomized trial of coenzyme Q10 in patients with statin myopathy: rationale and study design. J Clin Lipidol 7(3): 187-193.

ISSN: 2574-1241

DOI: $10.26717 /$ BJSTR.2020.25.004272

Simon Wernhart. Biomed J Sci \& Tech Res

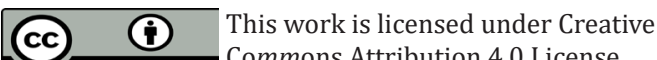

Submission Link: https://biomedres.us/submit-manuscript.php
22. Martucci G, Mc Nally D, Parekh D, Zajic P, Tuzzolino F, et al. (2019) Trying to identify who may benefit most from future vitamin D intervention trials: a post hoc analysis from the VITDAL-ICU study excluding the early deaths. Crit Care 23(1): 200.

23. Verdoia M, Pergolini P, Rolla R, Nardin M, Schaffer A, et al. (2017) Novara Atherosclerosis Study Group (NAS). Impact of high-dose statins on vitamin D levels and platelet function in patients with coronary artery disease. Thromb Res 150: 90-95

24. Ovesjö ML, Skilving I, Bergman P, Rane A, Ekström L (2016) Low Vitamin D Levels and Genetic Polymorphism in the Vitamin D Receptor are Associated with Increased Risk of Statin-Induced Myopathy. Basic Clin Pharmacol Toxicol 118(3): 214-218.

$\begin{array}{ll}\text { BIOMEDICAL } & \text { Assets of Publishing with us } \\ \text { RESEARCHES } & \text { - Global archiving of articles } \\ \text { - Immediate, unrestricted online access }\end{array}$

